University of Wollongong

Research Online

Faculty of Engineering and Information

Faculty of Engineering and Information

Sciences - Papers: Part A

Sciences

2013

Reversing port rotation directions in a container liner shipping network

Shuaian Wang

University of Wollongong, shuaian@uow.edu.au

Qiang Meng

National University of Singapore

Follow this and additional works at: https://ro.uow.edu.au/eispapers

Part of the Engineering Commons, and the Science and Technology Studies Commons

Research Online is the open access institutional repository for the University of Wollongong. For further information contact the UOW Library: research-pubs@uow.edu.au 


\title{
Reversing port rotation directions in a container liner shipping network
}

\author{
Abstract \\ Reversing port rotation directions of ship routes is a practical alteration of container liner shipping \\ networks. The port rotation directions of ship routes not only affect the transit time of containers, as has \\ been recognized by the literature, but also the shipping capacity and transshipment cost. This paper aims \\ to obtain the optimal port rotation directions that minimize the generalized network-wide cost including \\ transshipment cost, slot-purchasing cost and inventory cost. A mixed-integer linear programming model \\ is proposed for the optimal port rotation direction optimization problem and it nests a minimum cost \\ multi-commodity network flow model. The proposed model is applied to a liner shipping network \\ operated by a global liner shipping company. Results demonstrate that real-case instances could be \\ efficiently solved and significant cost reductions are gained by optimization of port rotation directions.

\section{Keywords} \\ port, rotation, directions, container, reversing, liner, network, shipping \\ Disciplines \\ Engineering | Science and Technology Studies

\section{Publication Details} \\ Wang, S. \& Meng, Q. (2013). Reversing port rotation directions in a container liner shipping network. \\ Transportation Research Part B: Methodological, 50 61-73.
}




\title{
Reversing Port Rotation Directions in a Container Liner Shipping Network
}

\author{
Shuaian Wang ${ }^{a *}$, Qiang Meng ${ }^{b}$ \\ ${ }^{a}$ School of Mathematics and Applied Statistics, University of Wollongong, Wollongong, NSW \\ 2522, Australia \\ ${ }^{b}$ Department of Civil and Environmental Engineering, National University of Singapore, \\ Singapore 117576
}

\begin{abstract}
Reversing port rotation directions of ship routes is a practical alteration of container liner shipping networks. The port rotation directions of ship routes not only affect the transit time of containers, as has been recognized by the literature, but also the shipping capacity and transshipment cost. This paper aims to obtain the optimal port rotation directions that minimize the generalized network-wide cost including transshipment cost, slot-purchasing cost and inventory cost. A mixed-integer linear programming model is proposed for the optimal port rotation direction optimization problem and it nests a minimum cost multicommodity network flow model. The proposed model is applied to a liner shipping network operated by a global liner shipping company. Results demonstrate that real-case instances could be efficiently solved and significant cost reductions are gained by optimization of port rotation directions.
\end{abstract}

Key Words: Liner shipping network design; port rotation directions; multi-commodity network flow; mixed-integer linear programming

\footnotetext{
${ }^{*}$ Corresponding author, Tel.: +61-2-4221 5770, Fax: +61-2-4221 4845

E-mail addresses: wangshuaian@gmail.com (S. Wang), ceemq@nus.edu.sg (Q. Meng)
} 


\section{Introduction}

Shipping lines transport containers from one port to another over their container liner shipping networks. A container liner shipping network operated by a particular shipping line comprises a set of ship routes with given service frequencies and strings of homogenous ships in terms of capacity and average sailing speed. A ship route can be defined by a sequence of ports called by ships where ships return to the first visited port after visiting the last port, referred to as a port rotation. In other words, a port rotation forms a directed loop with either a clockwise or a counter-clockwise direction. In practice, liner ship routes are mostly asymmetric. For example, OOCL (2012) operates 14 trans-Pacific ship routes, among which 12 are asymmetric, one of which is shown in Fig. 1. There are three possible reasons for the phenomenon of asymmetric ship routes: (i) Container ships can sail almost freely at sea, and visiting one more port needs a detour, resulting in additional time and cost at sea. (ii) Each call at a port involves cost and time, such as fixed charge for calling, pilotage, towage, mooring and unmooring. (iii) The world trade is unbalanced: the volume of export containers at a port can be significantly different from that of import containers.

$<$ Insert Figure 1 here $>$

\subsection{Generalized network-wide cost}

At the network level, there are three costs associated with container routing. The first one is transshipment cost. It is estimated that one third of the laden container throughput in the 
world in 2010 is made up of transshipped containers (Vernimmen et al., 2007). Transshipment cost of containers at transshipment ports is significant: it varies from several tens to several hundreds of USD per container (Fung, 2009), depending on the transshipment port and the type of containers to transship. The second one is slot-purchasing cost. If a liner shipping company cannot transport all the containers by its own ships, it may purchase ship slots from other shipping companies. This practice is common among shipping lines, especially shipping lines in an alliance (Alix et al., 1999; Maersk Line, 2012).

The transshipment cost and slot-purchasing cost are generally borne by shipping lines. There is another cost that is related to container routing - inventory cost of cargo in containers - which is borne by shippers (customers). The inventory cost of containers in the shipping process from origin ports to destination ports cannot be neglected. For instance, Notteboom (2006) estimated that one day delay of a 4,000-TEU (twenty-foot equivalent unit) ship implies a total cost of 57, 000 Euros associated with the cargos in the containers; Bakshi and Gans (2010) estimated the inventory cost of containerized cargo at 0.5 per cent the value of the cargo per day. Although the inventory cost is not directly borne by shipping lines, shipping lines should take it into account because providing shorter transit time and thereby reducing the inventory cost of customers would increase shipping lines' market share. Therefore, liner shipping companies seek to design their shipping services to minimize the generalized network-wide cost consisting of transshipment cost, slot-purchasing cost, and inventory cost. 


\subsection{Impact analysis of reversing port rotation directions on the generalized network- wide cost}

When the port rotation of a ship route is asymmetric, the direction of the port rotation, either clockwise or counter-clockwise, would have a significant impact on level of service and operations. First, the transit time of containers from origin to destination may be different. For instance, the direction of the port rotation shown in Fig. 1 is counter-clockwise, and a ship visits Pusan, Los Angeles and Oakland sequentially. If the direction is designed to be clockwise, then the transit time of containers from Pusan to Los Angeles will be longer, and the transit time from Pusan to Oakland will be shorter. As pointed out by Notteboom (2006), major export ports are usually the last port of call in a region, and major import ports are usually the first port of call in a region, so that the overall transit time is minimal. In Fig. 1, because there are more imported containers at Los Angeles than Oakland, Los Angeles is visited before Oakland in the port rotation.

Second, port rotation directions affect the shipping capacity of liner ship routes. As shown in Fig. 2 (a), the existing demands of 3000 TEUs from port 1 to port 3, 3000 TEUs from port 2 to port 1 , and 3000 TEUs from port 3 to port 2, cannot be satisfied by the ship route in Fig. 2 (a). However, if its direction is clockwise, then the demands can be fulfilled.

$<$ Insert Figure 2 here $>$

Third, because of the impact of port rotation directions on shipping capacity, they also have a bearing on transshipment cost. For example, due to the inappropriate direction of ship 
route 1 in Fig. 2 (b), some containers have to be transshipped at ports 2, 3, and 4, resulting in additional transshipment costs.

\subsection{Port rotation direction optimization problem}

Because of the importance of port rotation directions on the generalized network-wide cost, a natural question is how to determine the port rotation directions to minimize the generalized network-wide cost. This is a new research problem with practical significance. In fact, we came up with the idea of reversing port rotation directions in the process of implementing a two-year joint research project with a global liner shipping company on its shipping service network design. Based on the weekly discussions with collaborators from the company, we found that although networks designed from scratch by academia using sophisticated operations research methods could outperform the existing network in terms of cost or capacity utilization, the global liner shipping company did not seriously consider implementing the designed network. This is because liner shipping companies cannot reshuffle their networks overnight. Dedicated container terminals, joint shipping services with alliances, direct call at ports adjacent to major customers, container handling contracts with port operators, and locations of the ships to be deployed all affect the flexibility of changing the shipping network. Therefore, the designed network is used only as a reference for the global liner shipping company.

When we proposed the concept of reversing port rotation directions, the collaborators from the company all agreed that this concept had not come to their mind before and was indeed implementable. In fact, changing the directions of port rotations is easy to implement 
and has a marginal impact on the operations of customers, port operators, shipping alliances, and the liner shipping company itself. For example, if OOCL plans to change the direction of the port rotation shown in Fig. 1, after a ship visits Shanghai (YAN) and Pusan, it simply visits Oakland, Los Angeles, Pusan, Shanghai (YAN), Shanghai (WGQ), Ningbo, Qingdao, Pusan, Oakland, Los Angeles, etc. All the ports that were visited before are still visited now, and all the ships that served the ship route before still serve the same ship route now. The collaborators from the global shipping company did make one comment that it would be impossible for the company to reverse the directions of many port rotations at the same time. A more practical version of the problem is to reverse the directions of port rotations of ship routes on a particular trade lane, e.g., Asia-Europe ship routes, or to reverse at most a certain number of port rotations in the current network. Motivated by industrial requirement, in this study, we focus on an existing container liner shipping network and minimize the generalized network-wide cost by reversing at most a certain number of port rotation directions of ship routes in the network.

The remainder of this paper is organized as follows. Section 2 reviews relevant literature. Section 3 describes the port rotation direction optimization problem. Section 4 builds mathematical models. Section 5 gives the results of numerical experiments based on an AsiaEurope-Oceania liner shipping network. Conclusions are presented in Section 6. For better readability, the notation is listed in the appendix. 


\section{Literature review}

There are few studies related to the port rotation directions of liner shipping services (Christiansen et al., 2004; Meng et al., 2013). Although the importance of the first and last ports of call in a region has been realized by researchers and practitioners (Lago et al., 2001; Notteboom, 2006), no quantitative analysis models are reported. In fact, many factors contribute to the choice of the first/last port of call in a region, especially at the network level. For example, in Fig. 3 (a), port 1 is more important than port 2. However, it may not make sense to call at port 1 prior to port 2 on all the three ship routes, unless port 1 significantly outweighs port 2. In Fig. 3 (b), port 1 is more important than each of port 2, port 7, and port 8. However, ports 2, 7, and 8 are adjacent to each other, and their collective throughput considerably exceeds that of port 1 . In such a situation, it may be more reasonable to visit ports 2,7 , and 8 prior to port 1 . Regarding the impact of port rotation directions on shipping capacity and transshipment cost, to the best of our knowledge, there are no research efforts that investigate or even propose these issues. In an extreme case, for a network with a total of $n$ ports of call, the maximum volume of containers that can be transported may be increased to $n-1$ times as large as the original if the port rotation directions are optimized. An example is shown in Fig. 4: if the port rotation direction is counter-clockwise as in Fig. 4 (a), then the optimal choice to ship as many containers as possible is to ship $5000 /(n-1)$ containers for all the origin-destination (O-D) port pairs. Since there are $n$ O-D pairs, the total shipped volume is $5000 n /(n-1)$. By contrast, if the port rotation direction is clockwise as in Fig. 4 (b), all the $5000 n$ containers can be shipped. 
$<$ Insert Figure 3 here $>$

$<$ Insert Figure 4 here $>$

Most studies on liner shipping services require fixed port rotations as input of the models (Dong and Song, 2009; Bell et al., 2011; Qi and Song, 2012; Song and Dong, 2012; Wang and Meng, 2012b; Brouer et al., 2013; Wang et al., 2013b). One line of literature relevant to the optimization of port rotation directions is port rotation design, which is usually referred to as liner ship route design or liner shipping network design; for example, Shintani et al. (2007), Agarwal and Ergun (2008), Alvarez (2009), Meng and Wang (2011), Meng et al. (2012), Reinhardt and Pisinger (2012). Nevertheless, none of these studies explicitly investigate the impact of the directions of port rotations. In fact, port rotation direction optimization could be considered as a type of highly constrained network design problem. Because of the constraints that are imposed, that is, because only the directions could be changed, the flexibility of the network is reduced compared with networks designed by conventional approaches. On the other hand, due to the constraints, port rotation direction optimization is easier from the methodological point of view. In fact, the liner shipping network design problem is strongly NP-hard (Agarwal and Ergun, 2008). According to the results of existing research efforts, it is already very challenging to obtain a good bound for practical-sized problems, not to speak of exactly solving them. In contrast, as will be shown in this study, practical-sized port rotation direction optimization problems can be solved efficiently to optimality. An optimal solution is desirable because liner shipping companies may make 
further analysis and alteration of their services. Suboptimal solutions would undermine the quality of the subsequent efforts.

According to the above literature review, we can conclude that the port rotation direction optimization problem that minimizes the generalized network-wide cost is a new and practical research topic that has not been addressed or proposed, and is therefore the focus of this study.

\section{Port rotation direction reversing operations}

We consider a liner container shipping company which operates a number of ship routes, denoted by the set $\mathcal{R}$, regularly serving a group of ports denoted by the set $\mathcal{P}$. Each ship route $r \in \mathcal{R}$ has a weekly service frequency and can be expressed by its port rotation:

$$
p_{r 1} \rightarrow p_{r 2} \rightarrow \cdots \rightarrow p_{r N_{r}} \rightarrow p_{r 1}
$$

where $N_{r}$ is the number of ports of call on the route and $p_{r i}$ is the $i^{\text {th }}$ port of call, $i=1,2, \cdots, N_{r}$. For example, the liner shipping network in Fig. 5 has three ship routes. Ship route 1 has three ports of call, ship route 2 has five ports of call, and ship route 3 has three ports of call. Note that in ship route 2, the port of Singapore is visited twice.

$<$ Insert Figure 5 here $>$

The transit time of containers from the $i^{\text {th }}$ port of call, $i=1,2, \cdots, N_{r}-1$ to the $(i+1)^{\text {th }}$ port of call on ship route $r \in \mathcal{R}$, is represented by $t_{r i} \cdot t_{r N_{r}}$ represents the transit time of containers from the $\left(N_{r}\right)^{\text {th }}$ port of call to the $1^{\text {st }}$ port of call. $t_{r i}$ is calculated based on the 
speeds of ships, distances between ports, and time spent at ports. The container capacity of all ships deployed on ship route $r \in \mathcal{R}$ is the same and is represented by $\mathrm{Cap}_{r}$.

Represent by $\mathcal{W}$ the set of O-D port pairs, $\mathcal{W} \subset \mathcal{P} \times \mathcal{P}$. The demand for O-D pair $(o, d) \in \mathcal{W}$ is denoted by $q^{o d}$ (TEUs). Containers may be transshipped from origins to destinations. For example, containers from Jakarta to Chennai in the liner shipping network in Fig. 5 will be transhipped at Singapore and Colombo as there is no direct service between Jakarta and Chennai. The transshipment cost at port $p \in \mathcal{P}$ is denoted by $\bar{c}_{p}$ (USD/TEU). We do not explicitly incorporate the loading cost at origin ports or discharge cost at destination ports because they are constant. The connection time at port $p$, which is the additional time spent at port $p$ due to transshipment, is denoted by $t_{p}^{\text {conn }}$ (hours). Note that here we make the simplifying assumption that the connection time at each transshipment port is a fixed number. In fact, the connection time depends on the schedules of the services and is between 0 and 7 days. However, when the port rotation direction is reversed, the schedule may need to change in view of the available berth time windows at each port. Therefore, to capture the exact connection time, one has to incorporate the available berth time windows at each port in models, making the models highly intractable. In sum, in this study we simplify the connection time for two reasons: (i) the connection time is between 0 and 7 days, and the daily inventory cost are usually much less than the transshipment cost; (ii) incorporating the available berth time windows will make the models highly intractable.

If the liner shipping company cannot transport all the containers by its own ships, it may purchase ship slots from other shipping companies. The cost for purchasing one slot for O-D pair $(o, d) \in \mathcal{W}$ is denoted by $g^{\text {od }}$ (USD/TEU). 
The inventory cost of containers in the shipping process from origin ports to destination ports cannot be neglected. To account for this objective, we assume that a cost denoted by $\alpha$ (USD/(TEU.hour)) is associated with the transit time of containers. To simplify the notation, we define that the slot purchasing cost $g^{\text {od }}$ (USD/TEU) already includes the cost associated with transit time.

The reversed port rotation of the ship route of Eq. (1) is

$$
p_{r 1} \rightarrow p_{r N_{r}} \rightarrow p_{r, N_{r}-1} \rightarrow \cdots \rightarrow p_{r 3} \rightarrow p_{r 2} \rightarrow p_{r 1}
$$

The liner shipping company determines which port rotations of ship routes in $\mathcal{R}$ to reverse, so as to minimize the generalized network-wide cost. In order to maintain consistent services, it would be impractical for global liner shipping companies to reverse the directions of many port rotations at the same time. A more practical version of the problem is to reverse the directions of port rotations of ship routes on a particular trade lane, e.g., Asia-Europe ship routes, or to reverse at most a certain number of port rotations in the current network. There is little difference when modeling these two types of problems. Therefore in this study we assume that a maximum of $\beta$ port rotations can reverse their direction, where $\beta$ is an input parameter provided by liner shipping companies. In practice, the number of $\beta$ is usually very small, e.g., 2 or 3, because a liner shipping company would sequentially change its network step by step rather than dramatically change the network in a short time period. 


\section{Mathematical models}

To reflect the decisions on port rotation directions, we define $x_{r}$ as a binary decision variable which equals 0 if the direction of ship route $r \in \mathcal{R}$ does not change and 1 otherwise. All these decision variables are grouped into the vector:

$$
\mathbf{x}=\left(x_{1}, x_{2}, \cdots, x_{|\mathcal{R}|}\right)
$$

where $|\mathcal{R}|$ is the cardinality of set $\mathcal{R}$. Let $C(\mathbf{x})$ represent the minimum generalized network-wide cost for a given $\mathbf{x}$. Next, we present how to calculate $C(\mathbf{x})$.

\subsection{Minimum generalized network-wide cost for given port rotation directions}

To calculate the minimum generalized network-wide cost $C(\mathbf{x})$ for given port rotation directions represented by vector $\mathbf{x}$, we need to determine the optimal container flow in the network. To this end, we construct a ship route-based multi-commodity flow (MCF) network, which is an extension of Wang et al. (2013a). Let $G(\mathbf{x})=(N(\mathbf{x}), A(\mathbf{x}))$ represent the MCF network, where $N(\mathbf{x})$ represents the set of nodes and $A(\mathbf{x})$ is the set $\operatorname{arcs}$. Let $N^{\text {call }}(\mathbf{x})$, $N^{\text {src }}(\mathbf{x})$, and $N^{\text {sink }}(\mathbf{x})$ represent the set of nodes in the MCF network that correspond to calls at a port, source nodes, and sink nodes, respectively. $N^{\text {call }}(\mathbf{x}), N^{\text {src }}(\mathbf{x})$, and $N^{\text {sink }}(\mathbf{x})$ are mutually exclusive and collectively exhaustive subsets of $N(\mathbf{x})$. Let $A^{\text {voy }}(\mathbf{x}), A^{\text {trans }}(\mathbf{x})$, $A^{\text {src }}(\mathbf{x}), A^{\text {sink }}(\mathbf{x})$, and $A^{\text {slot }}(\mathbf{x})$ represent the set of arcs in the MCF network that correspond to voyages, transshipment operations, arcs from source nodes to nodes in $N^{\text {call }}(\mathbf{x})$, arcs from nodes in $N^{\text {call }}(\mathbf{x})$ to sink nodes, and arcs from source nodes to sink nodes that represent slotpurchasing operations, respectively. $A^{\text {voy }}(\mathbf{x}), A^{\text {trans }}(\mathbf{x}), A^{\text {src }}(\mathbf{x}), A^{\text {sink }}(\mathbf{x})$, and $A^{\text {slot }}(\mathbf{x})$ are mutually exclusive and collectively exhaustive subsets of $A(\mathbf{x})$. To construct the MCF network, we develop the following method.

\section{Ship Route-Based MCF Network Construction Method}


Step 1 (Construct $N^{\text {call }}(\mathbf{x})$ and $A^{\text {voy }}(\mathbf{x})$ ): Scan the port rotation of each ship route in set $\mathcal{R}$. Note that some ship routes in $\mathcal{R}$ have reversed their port rotation directions according to the value of vector $\mathbf{x}$. Construct a node for each port of call, and all the nodes form the set $N^{\text {call }}(\mathbf{x})$. Construct a voyage arc for each voyage leg, and all the voyage arcs form the set $A^{\mathrm{voy}}(\mathbf{x})$.

Step 2 (Construct $N^{\mathrm{src}}(\mathbf{x})$ and $A^{\mathrm{src}}(\mathbf{x})$ ): Scan all the ports in set $\mathcal{P}$. For a port $p \in \mathcal{P}$, if there exists $d \in \mathcal{P}$ satisfying $(p, d) \in \mathcal{W}$, that is, port $p \in \mathcal{P}$ is the origin port for some O-D pairs, construct a node for port $p \in \mathcal{P}$ denoted by $n_{p}^{\text {src }}$. All containers originating from port $p \in \mathcal{P}$ are treated as from the source node $n_{p}^{\text {src }}$ in the MCF network. Construct an arc from $n_{p}^{\text {src }}$ to each of the nodes in $N^{\text {call }}(\mathbf{x})$ that represent calls at port $p \in \mathcal{P}$. All the newly constructed nodes $n_{p}^{\text {src }}, p \in \mathcal{P}$ form the set $N^{\text {src }}(\mathbf{x})$ and all the newly constructed arcs form the set $A^{\mathrm{src}}(\mathbf{x})$.

Step 3 (Construct $N^{\text {sink }}(\mathbf{x})$ and $A^{\text {sink }}(\mathbf{x})$ ): Scan all the ports in set $\mathcal{P}$. For a port $p \in \mathcal{P}$, if there exists $o \in \mathcal{P}$ satisfying $(o, p) \in \mathcal{W}$, that is, port $p \in \mathcal{P}$ is the destination port for some O-D pairs, construct a node for port $p \in \mathcal{P}$ denoted by $n_{p}^{\text {sink }}$. All containers destined for port $p \in \mathcal{P}$ are treated as for the sink node $n_{p}^{\text {sink }}$ in the MCF network. Construct an arc from each of the nodes in $N^{\text {call }}(\mathbf{x})$ that represent calls at port $p \in \mathcal{P}$ to node $n_{p}^{\text {sink }}$. All the newly constructed nodes $n_{p}^{\text {sink }}, p \in \mathcal{P}$ form the set $N^{\text {sink }}(\mathbf{x})$ and all the newly constructed arcs form the set $A^{\text {sink }}(\mathbf{x})$.

Step 4 (Construct $A^{\text {slot }}$ ): Scan all the O-D pairs in set $\mathcal{W}$. For each O-D pair $(o, d) \in \mathcal{W}$, construct an arc from the source node in $N^{\mathrm{src}}(\mathbf{x})$ that corresponds to port $o \in \mathcal{P}$ to 
the sink node in $N^{\text {sink }}(\mathbf{x})$ that corresponds to port $d \in \mathcal{P}$. All these arcs form the set $A^{\text {slot }}(\mathbf{x})$.

Step 5 (Construct $A^{\text {trans }}(\mathbf{x})$ ): Scan all the ports in set $\mathcal{P}$. If port $p \in \mathcal{P}$ is visited more than once, that is, if there are at least two nodes in $N^{\text {call }}(\mathbf{x})$ that correspond to port $p \in \mathcal{P}$, construct two arcs between any two nodes in $N^{\text {call }}(\mathbf{x})$ that represent calls at port $p \in \mathcal{P}$. All the newly constructed arcs form the set $A^{\text {trans }}(\mathbf{x})$

The set of O-D pairs in the MCF network can be represented by:

$$
\hat{W}(\mathbf{x})=\left\{\left(n_{o}^{\mathrm{scc}}, n_{d}^{\mathrm{sink}}\right) \mid(o, d) \in \mathcal{W}\right\} \subset N(\mathbf{x}) \times N(\mathbf{x})
$$

and the demand between any two node pairs in the MCF network:

$$
\begin{aligned}
& \hat{q}^{n_{o}^{\text {scr }} n_{d}^{\text {sink }}}=q^{o d}, \forall(o, d) \in \mathcal{W} \\
& \hat{q}^{n_{1} n_{2}}=0, \forall\left(n_{1}, n_{2}\right) \notin \hat{W}(\mathbf{x})
\end{aligned}
$$

We summarize the cost and capacity associated with each type of arc in Table 1 . Note that strictly speaking, the arc cost $c_{m n}$ and capacity $\mathrm{Cap}_{m n}$ should also be written as $c_{m n}(\mathbf{x})$ and $\mathrm{Cap}_{m n}(\mathbf{x})$, respectively. For simplicity, we use $c_{m n}$ and $\mathrm{Cap}_{m n}$ without causing misunderstandings.

$<$ Insert Table 1 here >

\section{An example for constructing a MCF network:}

Consider the network shown in Fig. 5. Suppose that there are only one O-D pair, $\mathcal{W}=\{(\mathrm{XM}, \mathrm{SG})\}$, and $\mathbf{x}=(0,0,0)$, that is, the port rotation directions are the same as Fig. 5 . 
A MCF network representation of this network is depicted in Fig. 6. To construct the MCF network, first, each call at a port in a week is represented by a node. Therefore, one physical port may correspond to more than one node, for example, Singapore corresponds to three nodes in Fig. 6 because it is visited three times a week. Voyage arcs between these nodes are added to represent the voyage of ships. Second, if a port is the origin of at least one O-D pair (XM in this example), add a node representing the port as the source, and add source arcs from the source node to all the nodes representing the calls at the port (arc 1 in this example). Third, if a port is the destination of at least one O-D pair (SG in this example), add a node representing the port as the sink, and add sink arcs from each of the nodes representing the calls at the port to the sink node (arcs 16, 17, and 18 in this example). The purpose of the source/sink nodes/arcs is to enable each commodity (containers of one O-D pair) to have a unique origin and destination. For example, containers from Xiamen to Singapore are considered to be from the source node representing Xiamen to the sink node representing Singapore in the MCF network in Fig. 6. Fourth, for each O-D pair, add a slot purchasing arc connecting the source node of the origin port to the sink node of the destination port (arc 26 in this example). Fifth, if a port is visited more than once, that is, if there is more than one node in the network representing the port, then transshipment arcs are added to represent the container transshipment operations. For example, arc 10 in Fig. 6 represents the container transshipment operation at Singapore from the ship visiting Singapore as the third port of call on ship route 1, to the ship visiting Singapore as the fifth port of call on ship route 2 (c.f. Fig. 5). The transshipment arcs are indispensable to formulate the container transshipment cost and the connection time. 
$<$ Insert Figure 6 here $>$

The MCF network in Fig. 6 is intuitive: all the demands are fixed and are from one node to another; all the costs and capacities are imposed on arcs. The MCF network in Fig. 6 may be further improved: the number of transshipment arcs may be too large at major transshipment ports such as Singapore and Hong Kong. If a port is visited $n$ times a week, then the number of transshipment arcs is: $n(n-1)$. For example, when $n=3$, the number of transshipment arcs is 6 (transshipment at Singapore in Fig. 6); when $n=4$, the number of transshipment arcs is 12, e.g., Fig. 7(a). The large number of transshipment arcs, which increases in a quadratic manner with $n$, would pose computational difficulties for obtaining the optimal container flow, and thereby the optimal port rotation directions. To address this problem, we add a dummy transshipment node for each transshipment port, as shown in Fig. 7(b), and add two arcs between each node representing a call at the port and the dummy transshipment node. With this technique, the number of transshipment arcs is $2 n$, which increases linearly with $n$. Note that the cost associated with transshipment arcs in Table 1 should be halved as in Fig. 7(b) a transshipment operation involves two transshipment arcs.

$<$ Insert Figure 7 here $>$

To formulate a multi-commodity network flow (MCNF) model that minimizes the total cost, we define $f_{m n}^{d}$ as a decision variable representing the total volume of containers (TEUs) 
that are destined for node $d \in N^{\text {sink }}(\mathbf{x})$ and flow on arc $(m, n) \in A(\mathbf{x})$ in the network. Again, strictly speaking, the definition of $f_{m n}^{d}$ should be dependent on $\mathbf{x}$. However, for simplicity, we use $f_{m n}^{d}$ instead. $C(\mathbf{x})$ can be calculated by solving the following minimum cost MCNF model:

$[\mathrm{MCNF}]$

$$
C(\mathbf{x})=\min _{f_{m n}^{d}} \sum_{(m, n) \in A(\mathbf{x})} c_{m n} \sum_{d \in N^{\text {sink }}(\mathbf{x})} f_{m n}^{d}
$$

subject to:

$$
\begin{gathered}
\sum_{(m, n) \in A} f_{m n}^{d}-\sum_{(n, m) \in A} f_{n m}^{d}=\left\{\begin{array}{c}
-\hat{q}^{n d}, n \neq d \\
\sum_{o \in N} \hat{q}^{o d}, n=d
\end{array}, \forall n \in N(\mathbf{x}), \forall d \in N^{\mathrm{sink}}(\mathbf{x})\right. \\
\sum_{d \in N^{\mathrm{sink}}} f_{m n}^{d} \leq \operatorname{Cap}_{m n}, \forall(m, n) \in A(\mathbf{x}) \\
f_{m n}^{d} \geq 0, \forall(m, n) \in A(\mathbf{x}), \forall d \in N^{\mathrm{sink}}(\mathbf{x})
\end{gathered}
$$

The objective function (6) minimizes the total cost on all the arcs. Eq. (7) is the flow conservation equation. Eq. (8) imposes the capacity constraint. Eq. (9) is the nonnegativity constraint. The vector $\mathbf{x}$ is implicitly considered in the construction of the MCF network.

\subsection{A mixed-integer linear programming model for the port rotation direction optimization problem}

Based on the model $[\mathrm{MCNF}]$, we build a mixed-integer linear programming (MILP) model for the port rotation direction optimization problem. To this end, we first construct a new set of ship routes denoted by $\mathcal{R}^{\prime}=\left\{r_{1}^{\prime}, r_{2}^{\prime}, \cdots, r_{|\mathcal{R}|}^{\prime}\right\}$, which is the set of ship routes in $\mathcal{R}$ with a reversed port rotation direction. For example, ship routes $r_{2}^{\prime}$ and $r_{2}$ represent the same port rotation with different directions. We then construct a MCF network for all ship routes in 
$\mathcal{R} \cup \mathcal{R}^{\prime}$. Fig. 8 uses a toy network to demonstrate the construction of the MCF network. Fig. 8(a) is the original network, which has two ship routes and two O-D pairs: $(\mathrm{CC}, \mathrm{SG})$ and $(\mathrm{SG}$, CC). To optimize the port rotation directions, we first copy each ship route and reverse the port rotation directions of the copied ship routes, and hence Fig. 8(b) has 4 ship routes. The subsequent construction work of the MCF network is similar to that of Fig. 6 modified by Fig. 7(b). The only difference is, some ports are visited only once in the original network, such as Port of CC. Although they have two copies in the MCF network, exactly one copy will be used. Therefore, no dummy transshipment nodes or transshipment arcs associated with them are needed.

\section{$<$ Insert Figure 8 here $>$}

Let set $A_{r}^{\text {voy }}$ represent the set of voyage arcs on ship route $r \in \mathcal{R}$, and $\bar{A}_{r}^{\text {voy }}$ represent the set of voyage arcs on ship route $r^{\prime} \in \mathcal{R}^{\prime}$, which is the same as ship route $r \in \mathcal{R}$ except that the port rotation direction is reversed. For example, in Fig. 8(b), $A_{r_{1}}^{\text {voy }}=\{1,2,3\}$, $\bar{A}_{r_{1}}^{\text {voy }}=\{7,8,9\}, A_{r_{2}}^{\text {voy }}=\{4,5,6\}$, and $\bar{A}_{r_{2}}^{\text {voy }}=\{10,11,12\}$. The feasible set of decision vector $\mathbf{x}$ is as follows:

$$
X=\left\{\left(x_{1}, x_{2}, \cdots, x_{|\mathcal{R}|}\right) \mid \sum_{r \in \mathcal{R}} x_{r} \leq \beta ; x_{r} \in\{0,1\}, \forall r \in \mathcal{R}\right\}
$$

The port rotation optimization problem can be formulated as a mixed-integer linear programming model:

[MILP]

$$
\min _{\mathbf{x} \in X, f_{m n}^{d}} \sum_{(m, n) \in A} c_{m n} \sum_{d \in N^{\text {sink }}} f_{m n}^{d}
$$

subject to: 


$$
\begin{gathered}
\sum_{(m, n) \in A} f_{m n}^{d}-\sum_{(n, m) \in A} f_{n m}^{d}=\left\{\begin{array}{c}
-\hat{q}^{n d}, n \neq d \\
\sum_{o \in N} \hat{q}^{o d}, n=d
\end{array}, \forall n \in N, \forall d \in N^{\text {sink }}\right. \\
\sum_{d \in N^{\text {sink }}} f_{m n}^{d} \leq \operatorname{Cap}_{m n}\left(1-x_{r}\right), \forall r \in \mathcal{R}, \forall(m, n) \in A_{r}^{\text {voy }} \\
\sum_{d \in N^{\text {sink }}} f_{m n}^{d} \leq \operatorname{Cap}_{m n} x_{r}, \forall r \in \mathcal{R}, \forall(m, n) \in \bar{A}_{r}^{\text {voy }} \\
f_{m n}^{d} \geq 0, \forall(m, n) \in A, \forall d \in N^{\text {sink }}
\end{gathered}
$$

In contrast to $[\mathrm{MCNF}]$ where the set of nodes $N(\mathbf{x})$ and the set of $\operatorname{arcs} A(\mathbf{x})$ depend on the decision $\mathbf{x}$, in [MILP] the set of nodes $N$ and the set of $\operatorname{arcs} A$ no longer depend on $\mathbf{x}$. Moreover, because $x_{r}$ is a binary variable, the set of $\operatorname{arcs}$ in $A_{r}^{\text {voy }}$ and the set of $\operatorname{arcs}$ in $\bar{A}_{r}^{\text {voy }}$ cannot both have flows.

For small-scale and medium-sized problems, we can use off-the-shelf MILP solvers to solve the model [MILP]. For large-scale problems, we can solve [MILP] by meta-heuristics. For example, in Genetic Algorithm, the port rotation directions could be randomly determined at first and the resulting model $[\mathrm{MCNF}]$ could be solved to evaluate the quality of the randomly determined port rotation directions. However, based on our computational experience, the problem could be efficiently solved to optimality for many real-case instances.

In the above model the available berth time windows at each port are not incorporated. In practice the berths at ports may be fully occupied on particular days (Imai et al., 2005; Goodchild and Daganzo, 2007; Kang et al., 2008; Giallombardo et al., 2010; Zhen et al., 2011). For example, many ports are busy on Sundays and Mondays because customers would transport the products manufactured from Monday to Friday to the ports to be exported. Therefore, if the direction of port rotation is changed, the resulting inter-arrival time between ports may need to change. This would further have implications on bunker consumption and 
emissions (Psaraftis and Kontovas, 2010; Kontovas and Psaraftis, 2011; Wang and Meng, 2012a; Song and $\mathrm{Xu}, 2012$ ). Hence, incorporating berth time windows in port rotation direction optimization is an interesting and worthwhile future research topic.

Finally, it should be pointed out that the optimization of port rotation directions cannot replace the conventional liner shipping network design. The purpose of optimizing port rotation directions is to improve the network while not resulting in dramatic changes. The optimization of port rotation directions can also be used as a procedure in conventional liner shipping network design approaches.

\section{Case study}

We apply the proposed model in Section 4 to an Asia-Europe-Oceania shipping network of a global liner shipping company. This network has a total of 46 ports, as shown in Fig. 9. The transshipment cost is assumed to be $\bar{c}_{p}=200 \mathrm{USD} / \mathrm{TEU}$ and the connection time is assumed to be $t_{p}^{\text {conn }}=3$ days for all ports. There are totally 652 O-D port pairs with container shipment demand. 12 ship routes are operated over these 46 ports, as shown in Table 2. Table 2 also shows the size of ships deployed on each ship route and the arrival time at each port of call.

$<$ Insert Figure 9 here $>$

<Insert Table 2 here> 
It should be noted that (i) it is the inter-arrival time between two ports of call that determines the inventory cost, and hence for simplicity the arrival time at the first port of call is set at 0 ; (ii) the first port of call is shown twice, for example, a ship on the first ship route in Table 2 will return to Yokohama in 336 hours, which means that the round-trip journey time is two weeks. The slot-purchasing cost $g^{\text {od }}$ is set at

$$
g^{o d}:=1000+0.2 \times \text { Distance between the two ports (n mile), } \forall(o, d) \in \mathcal{W}
$$

The maximum number of port rotations whose directions can be reversed is $\beta=3$. The model [MILP] can be efficiently solved using CPLEX-12.1 with default settings, running on a 3 GHz Dual Core PC with 4 GB of RAM, in less than 1 minute, and hence the CPU time is not reported here.

We conduct experiments on six test instances. In the first three instances, the total container shipment demand of the 652 O-D port pairs is 22054 TEUs (the column "Total demand" in Table 3), in the last three instances, the total demand is 17643 TEUs, $80 \%$ of the first three instances. In instances 1 and 4, the cost associated with the transit time of containers is $\alpha=0.5 \mathrm{USD} /(\mathrm{TEU} \cdot$ hour), in instances 2 and 5 we set $\alpha=1$, in instances 3 and 6 we set $\alpha=2$. For each of the six instances, we calculate the minimum total cost of the original network and the optimized network where at most $\beta=3$ port rotations have changed their directions.

We report the results of the six test instances in Table 3. The column "Total demand" is the total container shipment demand of the 652 O-D port pairs, and the column " $\alpha$ " is the cost associated with the transit time of containers. For each of the six instances, the row " $\beta=0$ " corresponds to the original network, the row " $\beta=3$ " corresponds to the optimized 
network where at most three port rotations have changed their directions, and the row "Imp" represents the relative improvement due to the change of port rotation directions. In particular, we report the optimal objective function of [MILP] (the column "Total cost" in 1000 USD), the total slot-purchasing cost (the column "Slot cost" in 1000 USD), the total volume of slots that are purchased (the column "\#slots" in TEUs), the sum of the total transshipment cost and inventory cost associated with connection time (the column "Transship cost" in 1000 USD), the total transshipment volume (the column "Transship volume" in TEUs), and the total inventory cost associated with transit time excluding the connection time at transshipment ports (the column "Cost of transit time" in 1000 USD). Table 3 also reports the port rotations whose directions are changed at the optimal solution (the column "Reversed ship routes").

The results demonstrate that the total network-wide cost is reduced between $3.5 \%$ and $4.9 \%$ among the instances, or between 311,000 and 1,177,000 USD/week. The reduction of total network-wide cost by optimization of port rotation directions is mainly attributed to the reduction of inventory cost. Consequently, the reduction of total cost is more evident when $\alpha$ is larger: the reduction of total cost is higher for instances 2 and 5 than instances 1 and 4 , respectively. In instances 3 and 6, because the inventory cost is very high, the liner shipping company tends to purchase more slots and hence the reduction in inventory cost is not as significant. Note that this observation is valid because we assume that the slot-purchasing cost does not change with the inventory cost in Eq. (16). The transshipment volume decreases in all these instances when the port rotation directions are optimized. This can be explained by Fig. 2 (b). Finally, we observe that the results are somewhat robust: the port rotations of ship routes 10 and 11 are reversed in the optimal solution, no matter what value $\alpha$ takes in 
$\{0.5,1.0,2.0\}$ and the total demand takes in $\{22054,17643\}$. This is inspiring for the liner shipping company because the parameters of inventory cost and demand cannot be predicted accurately.

$<$ Insert Table 3 here>

\section{Conclusions}

This paper has proposed for the first time that port rotation directions in a liner shipping network not only affect the transit time of containers, but also the shipping capacity and transshipment cost. Because of the importance of port rotation directions, we have addressed the port rotation direction reversing problem, which is a type of liner shipping network design problem. The port rotation direction reversing problem minimizes the total network-wide cost consisting of transshipment cost, slot-purchasing cost, and inventory cost. The significance of the problem lies in that the optimization results of port rotation directions are readily acceptable by a liner shipping company because changing the directions of port rotations is easy to implement and has a marginal impact on the operations of customers, port operators, shipping alliances, and the liner shipping company itself. The port rotation direction optimization problem is formulated as a mixed-integer linear programming model based on a minimum cost multi-commodity network flow model. Real-case studies based on the AsiaEurope-Oceania shipping network of a global liner shipping company demonstrate that the proposed models could be solved efficiently to optimality and the cost reduction by optimization of port rotation directions is significant. In this study, the available berth time 
windows at each port are not incorporated. Hence, incorporating berth time windows in port rotation direction optimization is an interesting and worthwhile future research topic.

\section{Appendix: List of Notation}

$\underline{\text { Sets }}$

$A$ : $\quad$ Set of arcs in the MCF network;

$A_{r}^{\text {voy }}: \quad \quad$ Set of voyage arcs on ship route $r \in \mathcal{R}$;

$\bar{A}_{r}^{\text {voy }}: \quad \quad$ Set of voyage arcs on ship route $r^{\prime} \in \mathcal{R}^{\prime}$;

$N: \quad$ Set of nodes in the MCF network;

$N^{\text {sink }}: \quad$ Set of dummy sink nodes;

$\mathcal{P}: \quad$ Set of ports;

$\mathcal{R}: \quad \quad \quad$ Set of ship routes;

$\mathcal{R}^{\prime}: \quad \quad \quad \quad$ Set of ship routes in $\mathcal{R}$ with a reversed port rotation direction;

$\mathcal{W}: \quad$ Set of O-D port pairs;

$\hat{W}: \quad$ Set of O-D pairs in the MCF network;

$X: \quad$ Feasible set of decision vector $\mathbf{x}$;

\section{Parameters}

$\alpha: \quad$ Cost (USD/(TEU.hour)) associated with the transit time of containers;

$\beta$ : $\quad$ Maximum number of port rotations whose directions can be reversed;

Cap $_{r}$ : $\quad$ Container capacity (TEUs) of the ships deployed on ship route $r \in \mathcal{R}$;

$c_{m n}: \quad$ Cost (USD/TEU) of $\operatorname{arc}(m, n) \in A$ in the MCF network;

$\mathrm{Cap}_{m n}: \quad$ Capacity (TEUs) of arc $(m, n) \in A$ in the MCF network;

$\bar{c}_{p}: \quad$ Transshipment cost (USD/TEU) at port $p \in \mathcal{P}$ 
$g^{\text {od }}: \quad$ Cost (USD/TEU) for purchasing slots for O-D pair $(o, d) \in \mathcal{W}$;

$n_{p}^{\text {src }}: \quad$ Dummy source node of port $p \in \mathcal{P}$

$n_{p}^{\text {sink }}: \quad$ Dummy sink node of port $p \in \mathcal{P}$

$N_{r}: \quad$ Number of ports of call on ship route $r$;

$q^{o d}: \quad$ Demand (TEUs) for O-D pair $(o, d) \in \mathcal{W}$;

$q^{m n}: \quad$ Demand (TEUs) for node pair $m \in N, n \in N$

$t_{r i}: \quad$ Transit time (h) of containers from the $i^{\text {th }}$ port of call to the next on ship route $r \in \mathcal{R}$

$t_{p}^{\text {conn }}: \quad$ Connection time (h) at port $p$;

\section{$\underline{\text { Decision variables }}$}

$x_{r}: \quad$ A binary decision variable which equals 0 if the direction of ship route $r \in \mathcal{R}$ does not change and 1 otherwise;

$f_{m n}^{d}: \quad$ The total volume of containers (TEUs) that are destined for node $d \in N^{\text {sink }}$ and flow on arc $(m, n) \in A$ in the MCF network;

\section{Others}

$C(\mathbf{x}): \quad$ Minimum network-wide cost (USD) resulting from decision $\mathbf{x}$;

$p_{r i}: \quad \quad \quad$ The $i^{\text {th }}$ port of call on ship route $r$;

\section{Acknowledgements}

The authors thank the two anonymous reviewers for their valuable comments and suggestions. This study is supported by the research grants FIRDS from University of 
Wollongong, and WBS No. R-302-000-014-720 from the NOL Fellowship Programme of Singapore.

\section{References}

Agarwal, R., Ergun O., 2008. Ship scheduling and network design for cargo routing in liner shipping. Transportation Science 42(2), 175-196.

Alix, Y., Slack, B., Comtois, C., 1999. Alliance or acquisition? Strategies for growth in the container shipping industry, the case of CP ships. Journal of Transport Geography 7(3), 203208.

Alvarez, J.F., 2009. Joint routing and deployment of a fleet of container vessels. Maritime Economics \& Logistics 11(2), 186-208.

Bakshi, N., Gans, N., 2010. Securing the containerized supply chain: analysis of government incentives for private investment. Management Science 56(2), 219-233.

Bell, M.G.H., Liu, X., Angeloudis, P., Fonzone, A., Hosseinloo, S.H., 2011. A frequency-based maritime container assignment model. Transportation Research Part B 45(8), 1152-1161.

Brouer, B.D., Dirksen, J., Pisinger, D., Plum, C.E.M., Vaaben, B., 2013. The Vessel Schedule Recovery Problem (VSRP) - A MIP model for handling disruptions in liner shipping. European Journal of Operational Research 224(2), 362-374.

Christiansen, M., Fagerholt, K., Ronen, D., 2004. Ship routing and scheduling: status and perspectives. Transportation Science 38(1), 1-18.

Dong, J.X., Song, D.P., 2009. Container fleet sizing and empty repositioning in liner shipping systems. Transportation Research Part E 45(6), 860-877. 
Fung, M., 2009. Does trigger point mechanism create monopoly power for Hong Kong container terminals? Maritime Policy \& Management 36(4), 325-336.

Giallombardo, G., Moccia, L, Salani, M., Vacca, I., 2010. Modeling and solving the Tactical Berth Allocation Problem. Transportation Research Part B 44(2), 232-245.

Goodchild, A.V., Daganzo, C.F., 2007. Crane double cycling in container ports: Planning methods and evaluation. Transportation Research Part B 41(8), 875-891.

Imai, A., Sun, X., Nishimura, E., Papadimitriou, S., 2005. Berth allocation in a container port: using a continuous location space approach. Transportation Research Part B 39(3), 199-221.

Kang, S., Medina, J.C., Ouyang, Y., 2008. Optimal operations of transportation fleet for unloading activities at container ports. Transportation Research Part B 42(10), 970-984.

Kontovas, C.A., Psaraftis, H.N., 2011. Reduction of emissions along the maritime intermodal container chain: operational models and policies. Maritime Policy and Management 38(4), 451-469.

Lago, A., Malchow, M., Kanafani, A., 2001. An analysis of carriers' schedules and the impact on port selection. Proceedings of the IAME 2001 Conference, Hong Kong, 123-137.

Notteboom, T.E., 2006. The time factor in liner shipping services. Maritime Economics and Logistics 8(1), 19-39.

$\begin{array}{llll}\text { Maersk } & \text { Line. } & \text { Vessel } & \text { sharing }\end{array}$ http://www.maerskline.com/link/?page=brochure\&path=/our_services/general_business_ter ms/Vessel\%20sharing\%20agreement. Accessed 22 Oct 2012.

Meng, Q., Wang, S., 2011. Liner shipping service network design with empty container repositioning. Transportation Research Part E 47(5), 695-708. 
Meng, Q., Wang, S., Liu, Z., 2012. Network design for shipping service of large-scale intermodal liners. Transportation Research Record 2269, 42-50.

Meng, Q., Wang, S., Andersson, H., Thun, K., 2013. Containership routing and scheduling in liner shipping: overview and future research directions. Transportation Science, in press.

OOCL. Service Routes. http://www.oocl.com/eng/ourservices/serviceroutes/tpt/. Accessed 28 July 2012.

Psaraftis, H.N., Kontovas, C.A., 2010. Balancing the economic and environmental performance of maritime transportation. Transportation Research Part D 15(8), 458-462.

Qi, X., Song, D.P., 2012. Minimizing fuel emissions by optimizing vessel schedules in liner shipping with uncertain port times. Transportation Research Part E 48(4), 863-880.

Reinhardt, L.B., Pisinger, D., 2012. A branch and cut algorithm for the container shipping network design problem. Flexible Services and Manufacturing Journal 24(3), 349-374.

Shintani, K., Imai, A., Nishimura, E., Papadimitriou, S., 2007. The container shipping network design problem with empty container repositioning. Transportation Research Part E 43(1), $39-59$.

Song, D.P., Dong, J.X., 2012. Cargo routing and empty container repositioning in multiple shipping service routes. Transportation Research Part B 46(10), 1556-1575.

Song, D.P. and Xu, J.J., 2012. An operational activity-based method to estimate CO2 emissions from container shipping considering empty container repositioning. Transportation Research Part D 17(1), 91-96. 
Vernimmen, B., Dullaert, W., Engelen, S., 2007. Schedule unreliability in liner shipping: origins and consequences for the hinterland supply chain. Maritime Economics and Logistics 9(3), 193-213.

Wang, S., Meng, Q., 2011. Schedule design and container routing in liner shipping. Transportation Research Record: Journal of the Transportation Research Board 2222, 25-33.

Wang, S., Meng, Q., 2012a. Liner ship route schedule design with sea contingency time and port time uncertainty. Transportation Research Part B 46(5), 615-633.

Wang, S., Meng, Q., 2012b. Sailing speed optimization for container ships in a liner shipping network. Transportation Research Part E 48(3), 701-714.

Wang, S., Meng, Q., Sun, Z., 2013a. Container routing in liner shipping. Transportation Research Part E 49(1), 1-7.

Wang, S., Meng, Q., Bell, M.G.H., 2013b. Liner ship route capacity utilization estimation with a bounded polyhedral container shipment demand pattern. Transportation Research Part B 47(1), 57-76.

Zhen, L., Chew, E.P., Lee, L.H., 2011. An integrated model for berth template and yard template planning in transshipment hubs. Transportation Science 45(4), 483-504. 


\section{List of Figures and Tables}

Fig. 1 An asymmetric ship route operated by OOCL (2012)

Fig. 2 Impact of port rotation directions on shipping capacity and transshipment cost

Fig. 3 Examples of difficult choices of the first/last port of call

Fig. 4 An extreme case showing the impact of port rotation directions on shipping capacity

Fig. 5 An illustrative liner shipping network (Wang and Meng, 2012a)

Fig. 6 A MCF network (Revised from Wang et al., 2013a)

Fig. 7 A modeling technique for reducing the number of transshipment arcs

Fig. 8 A MCF network for the MILP formulation

Fig. 9 Asia-Europe-Oceania shipping network of a global liner shipping company (Source: Wang and Meng, 2011)

Table 1 Summary of flow costs and capacities of arcs in the MCF network

Table 2 The existing 12 port rotations and deployed ships

Table 3 Computational results

(All figures are in color on the web only. Please use black and white figures in the printed version) 


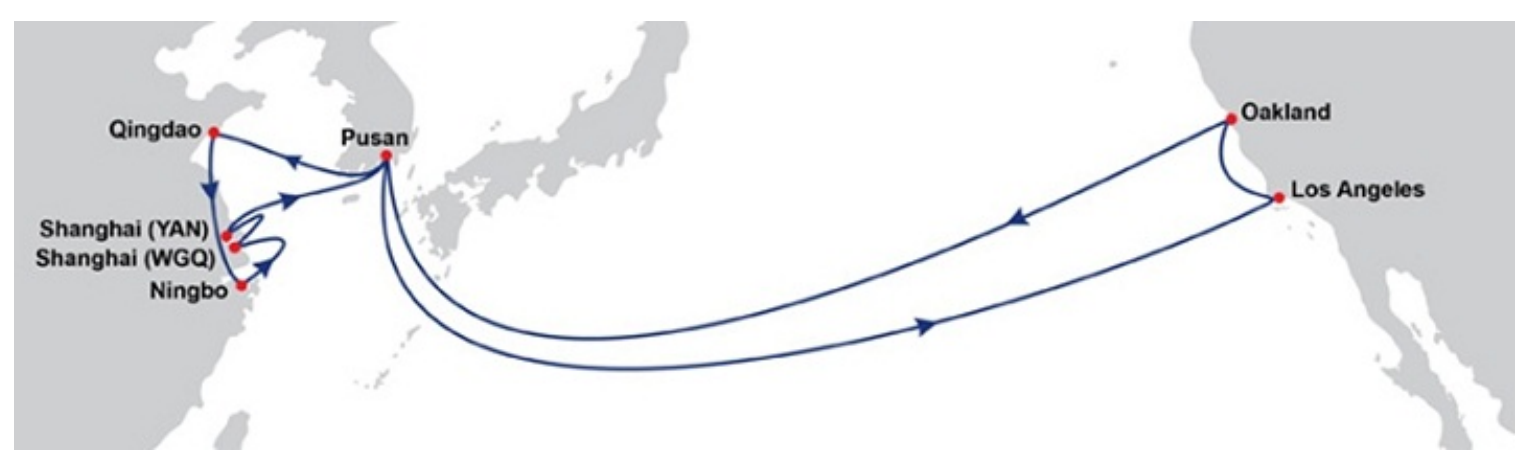

Fig. 1 An asymmetric ship route operated by OOCL (2012)

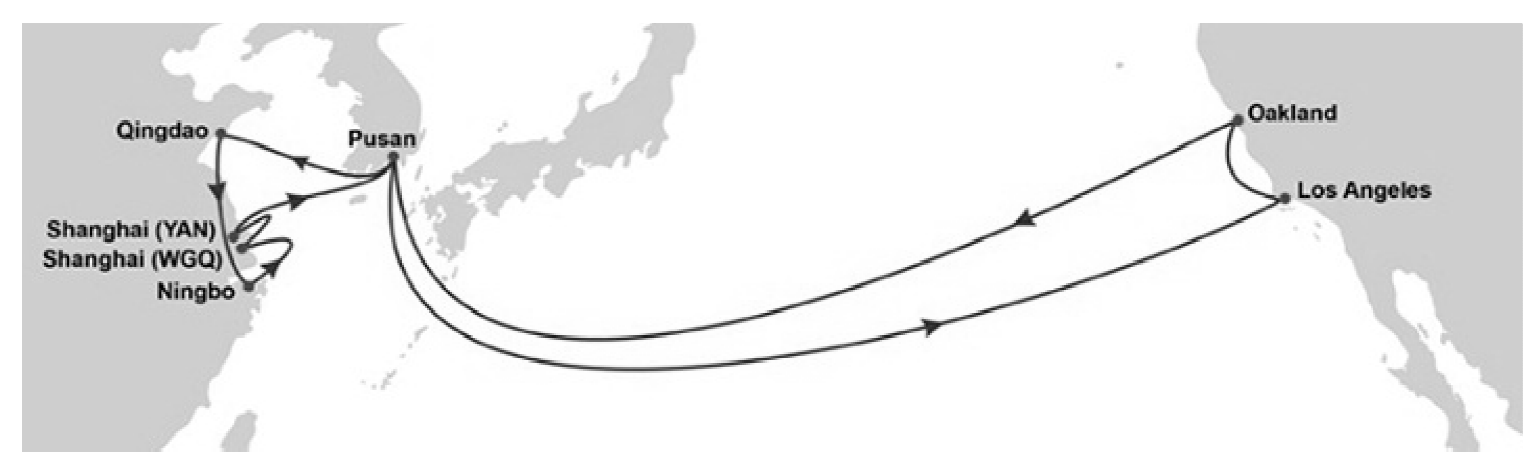

(Black and white version of Fig. 1 for the printed version)

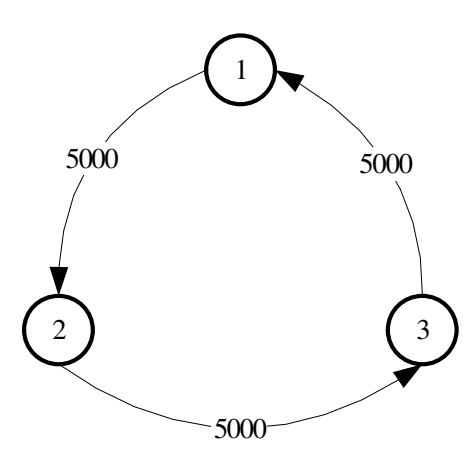

(a)

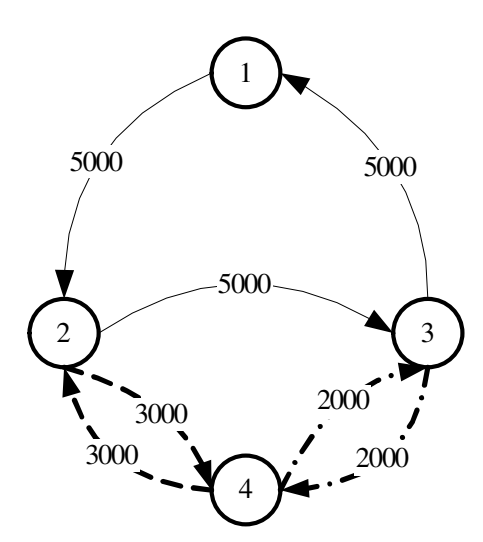

(b)

Fig. 2 Impact of port rotation directions on shipping capacity and transshipment cost 


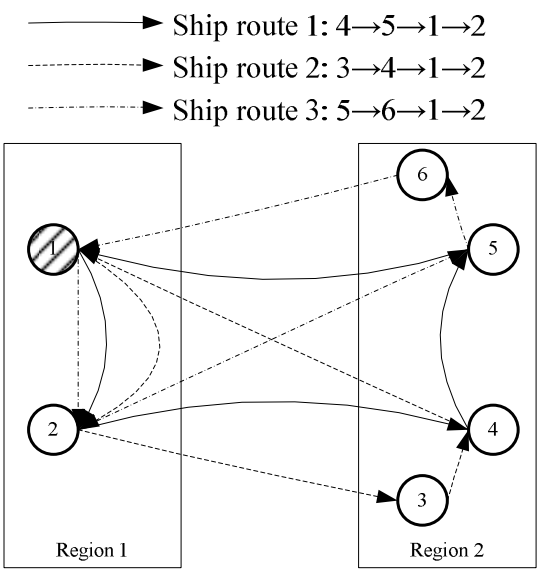

(a)
Ports 2, 7, 8 are next to each other

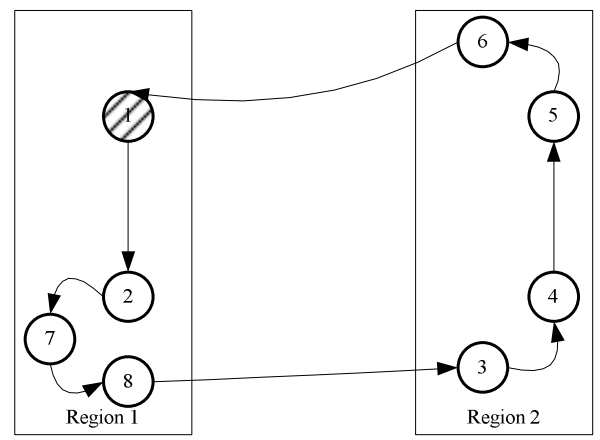

(b)

Fig. 3 Examples of difficult choices of the first/last port of call

Demand: $\quad 1 \rightarrow n: 5000$

$2 \rightarrow 1: 5000,3 \rightarrow 2: 5000$
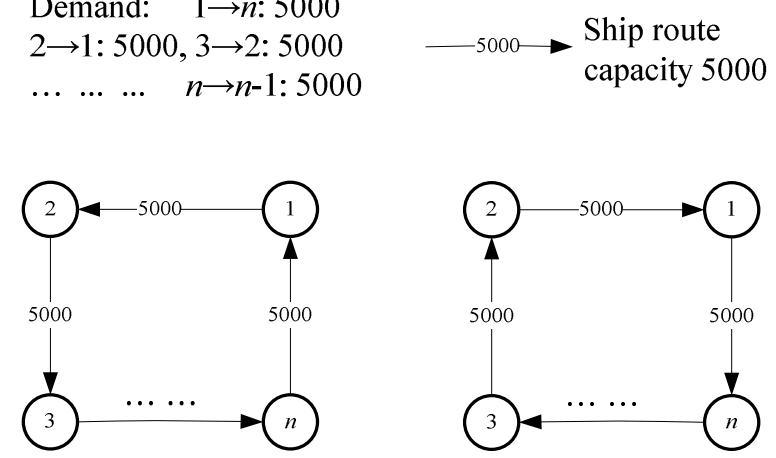

Optimal routing:
$1 \rightarrow n: 5000 /(n-1)$
$2 \rightarrow 1: 5000 /(n-1)$
$3 \rightarrow 2: 5000 /(n-1)$
$\ldots$
$n \rightarrow n-1: 5000 /(n-1)$
Total volume: $5000 n /(n-1)$

(a) counter-

clockwise direction
Optimal routing:

$1 \rightarrow n: 5000$

$2 \rightarrow 1: 5000$

$3 \rightarrow 2: 5000$

$n \rightarrow n-1: 5000$

Total volume: $5000 n$

(b) clock-wise direction

Fig. 4 An extreme case showing the impact of port rotation directions on shipping capacity 


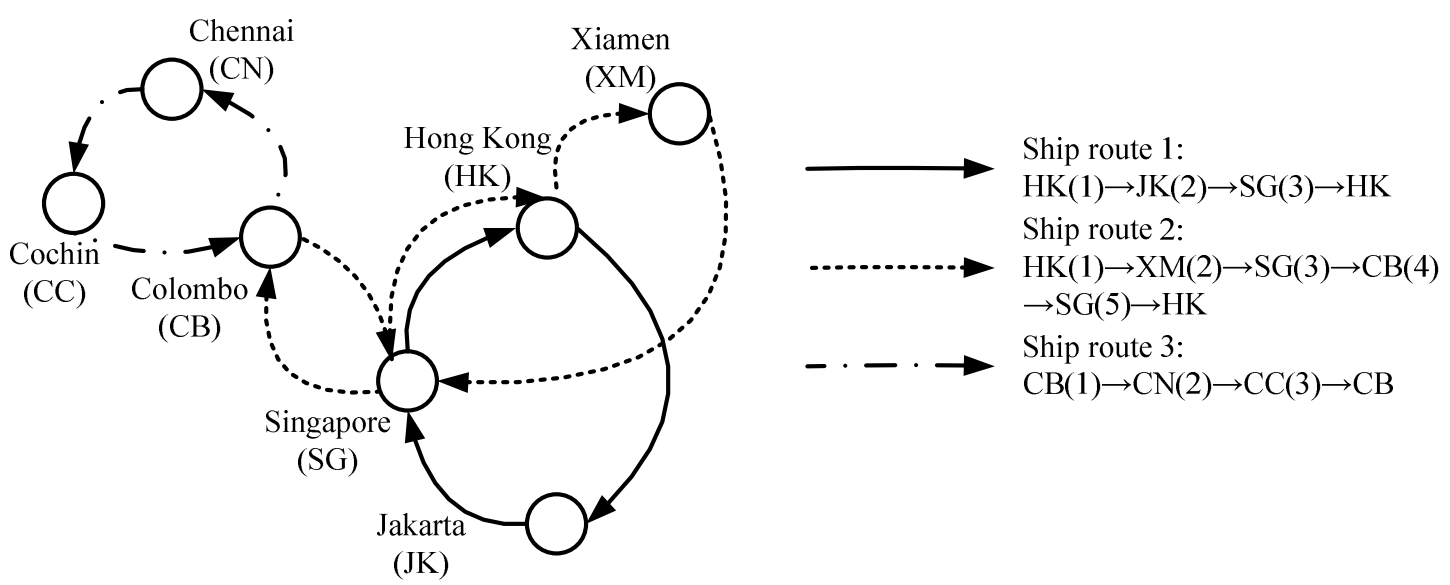

Fig. 5 An illustrative liner shipping network (Wang and Meng, 2012a)

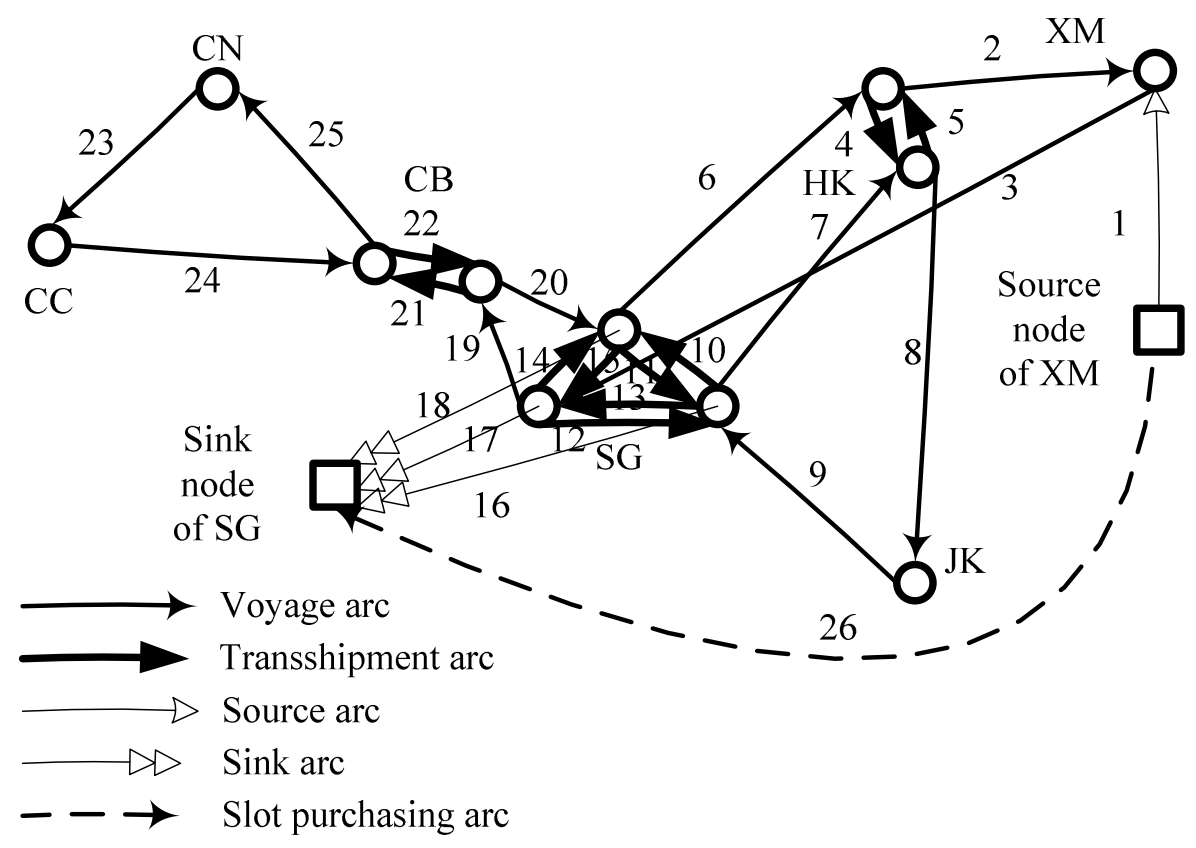

Fig. 6 A MCF network (Revised from Wang et al., 2013a) 


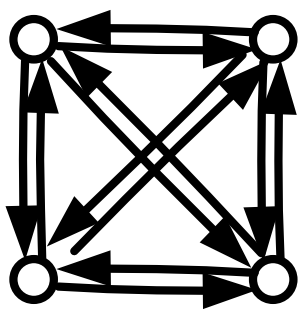

(a)

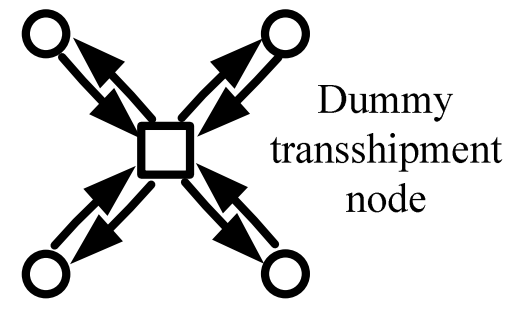

(b)

Fig. 7 A modeling technique for reducing the number of transshipment arcs
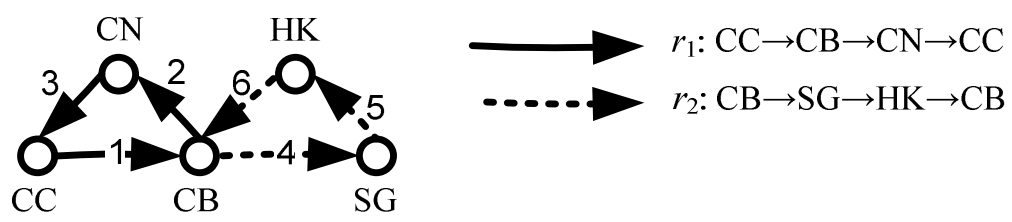

(a) A liner shipping network with two ship routes and two O-D pairs (CC, SG) and (SG, CC)

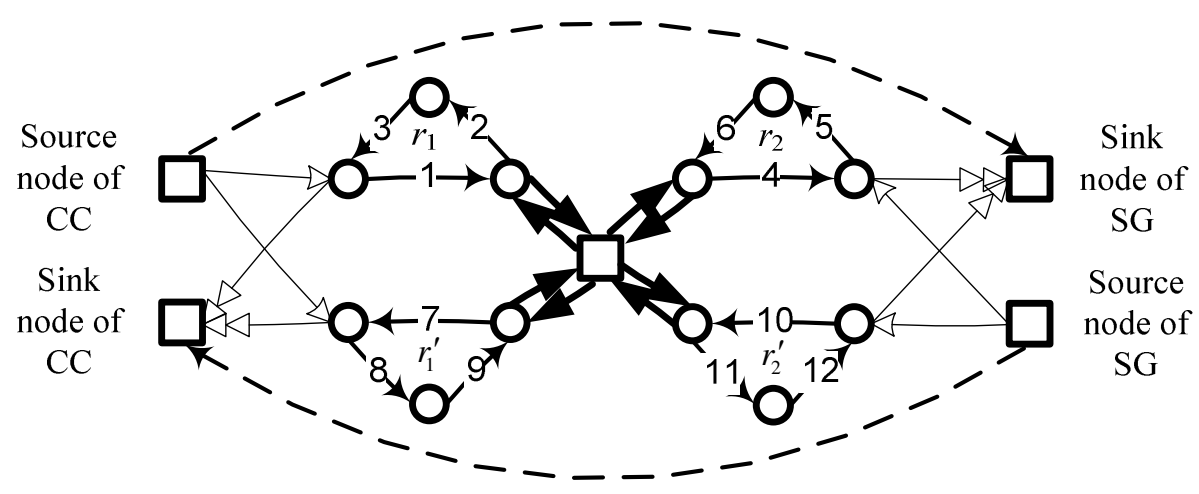

(b) A MCF network representation for port rotation direction optimization

Fig. 8 A MCF network for the MILP formulation 


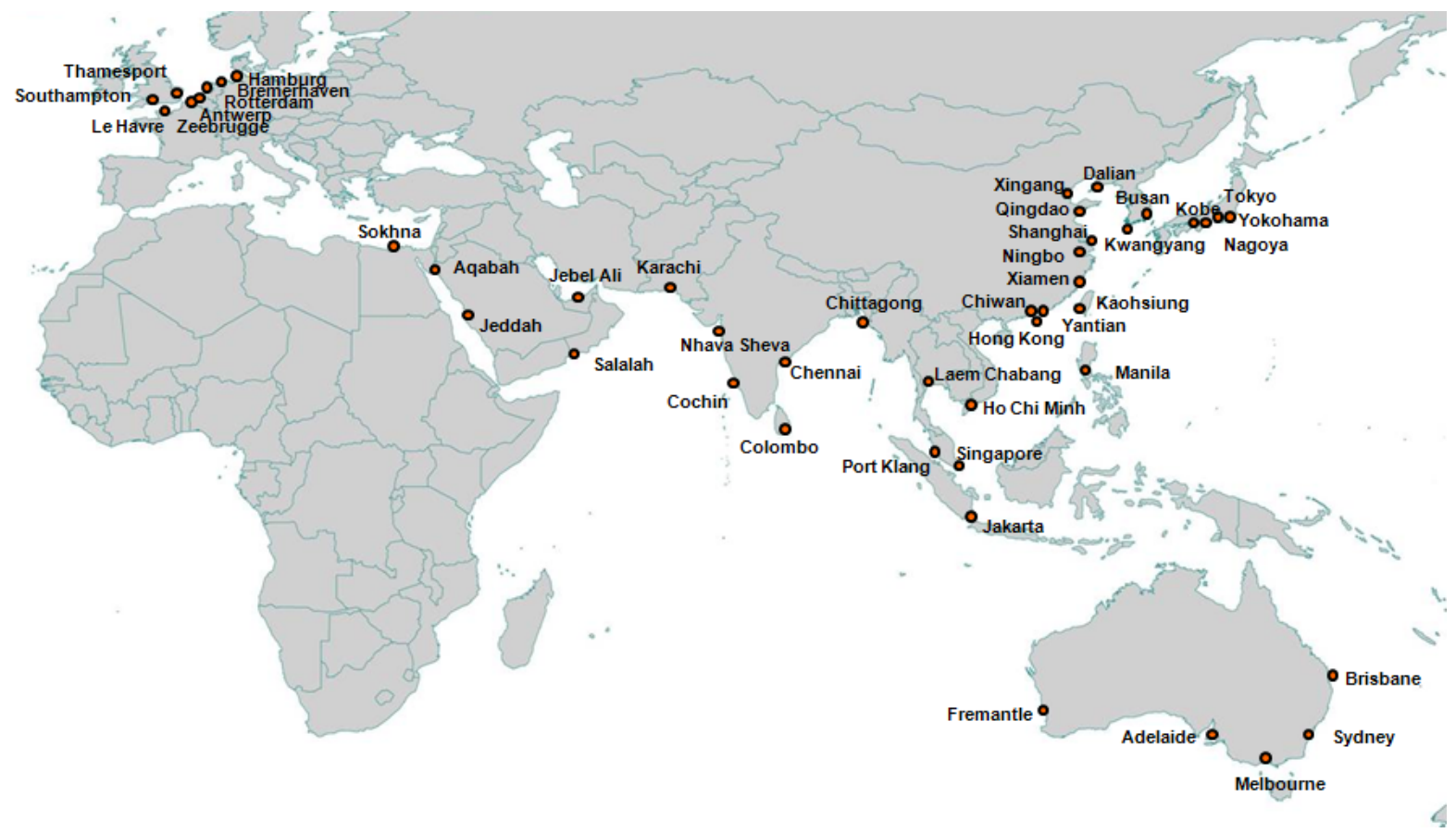

Fig. 9 Asia-Europe-Oceania shipping network of a global liner shipping company (Source: Wang and Meng, 2011)

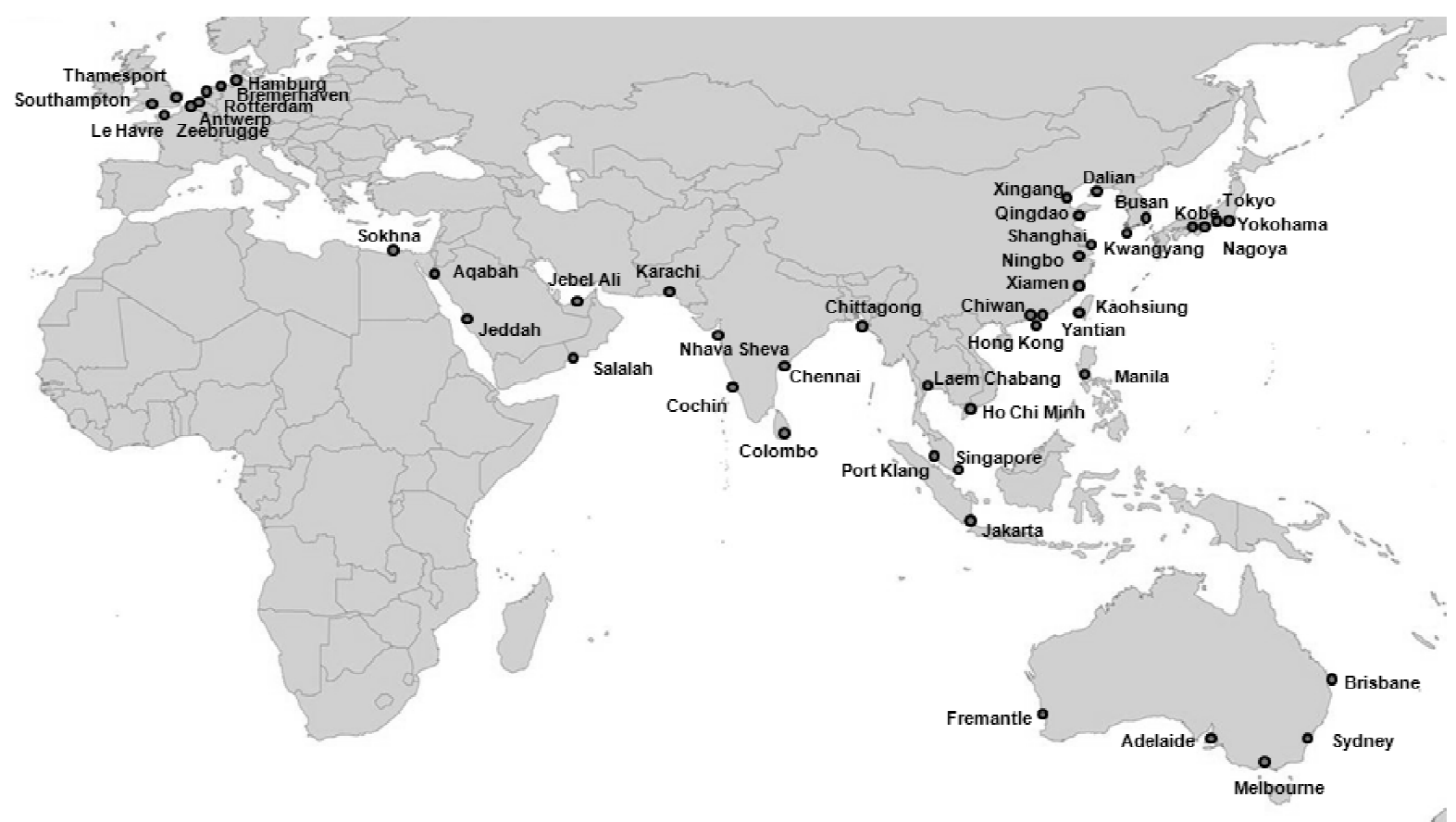

(Black and white version of Fig. 9 for the printed version) 
Table 1 Summary of flow costs and capacities of arcs in the MCF network

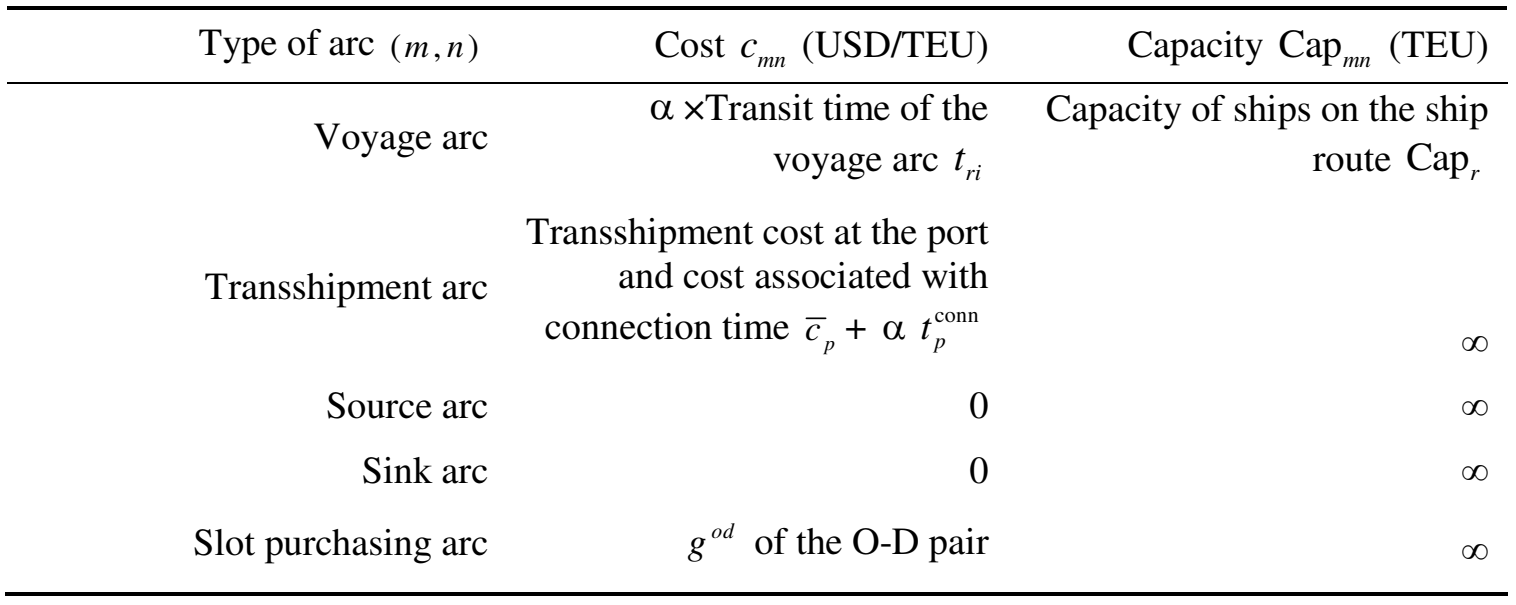

Table 2 The existing 12 port rotations and deployed ships

\begin{tabular}{|c|c|c|}
\hline ID & $\begin{array}{l}\text { Ship size } \\
\text { (TEUs) }\end{array}$ & Port rotation and arrival time (hour) \\
\hline 1 & 1500 & $\begin{array}{l}\text { Yokohama(0) } \rightarrow \text { Tokyo(25) } \rightarrow \operatorname{Nagoya(67)~} \rightarrow \text { Kobe(112) } \rightarrow \text { Shanghai(210) }-> \\
\text { Yokohama(336) }\end{array}$ \\
\hline 2 & 1500 & $\begin{array}{l}\text { Ho Chi Minh(0) -> Laem Chabang(83) -> Singapore(184) -> Port Klang(227) -> Ho Chi } \\
\text { Minh(336) }\end{array}$ \\
\hline 3 & 1500 & $\begin{array}{l}\text { Brisbane(0) }->\text { Sydney(56) }->\text { Melbourne(120) }->\text { Adelaide(181) }->\text { Fremantle(309) }-> \\
\text { Jakarta(468) }->\text { Singapore(530) }->\text { Brisbane(840) }\end{array}$ \\
\hline 4 & 3000 & $\begin{array}{l}\text { Manila(0) -> Kaohsiung(78) -> Xiamen(119) -> Hong Kong(170) -> Yantian(196) -> } \\
\text { Chiwan(222) -> Hong Kong(247) -> Manila(336) }\end{array}$ \\
\hline 5 & 1500 & $\begin{array}{l}\text { Dalian(0) } \rightarrow \text { Xingang(37) } \rightarrow \text { Qingdao(88) } \rightarrow \text { Shanghai(134) } \rightarrow \text { Ningbo(165) } \rightarrow> \\
\text { Shanghai(196) }->\text { Kwangyang(247) }->\text { Busan(276) } \rightarrow \text { Dalian(336) }\end{array}$ \\
\hline 6 & 1500 & $\begin{array}{l}\text { Chittagong }(0)->\text { Chennai(78) }->\text { Colombo(139) }->\text { Cochin(182) }->\text { Nhava Sheva(252) }-> \\
\text { Cochin(321) }->\text { Colombo(364) }->\text { Chennai(425) }->\text { Chittagong(504) }\end{array}$ \\
\hline 7 & 1500 & $\begin{array}{l}\text { Sokhna(0) }->\text { Aqabah(44) } \rightarrow \text { Jeddah(112) } \rightarrow \text { Salalah(236) } \rightarrow \text { Karachi(330) } \rightarrow \text { Jebel } \\
\text { Ali(408) }->\text { Salalah(500) }->\text { Sokhna(672) }\end{array}$ \\
\hline 8 & 3000 & 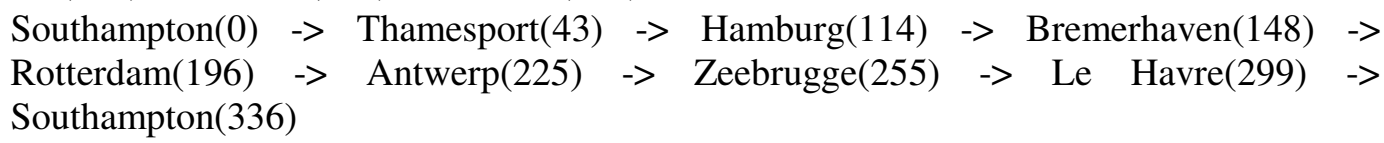 \\
\hline 9 & 3000 & $\begin{array}{l}\text { Port Klang(0) }->\text { Singapore(38) }->\text { Jakarta(98) }->\text { Kaohsiung(267) }->\text { Busan(359) }-> \\
\text { Kaohsiung(452) }->\text { Hong Kong(502) }->\text { Chiwan(527) }->\text { Port Klang(672) }\end{array}$ \\
\hline 10 & 10000 & $\begin{array}{l}\text { Southampton(0) }->\text { Sokhna(154) }->\text { Salalah(256) }->\text { Colombo(348) }->\text { Singapore(437) }-> \\
\text { Hong Kong(519) }->\text { Xiamen(554) }->\text { Shanghai(598) }->\text { Busan(641) }->\text { Dalian(685) }-> \\
\text { Xingang(717) }->\text { Qingdao(757) }->\text { Shanghai(793) }->\text { Hong Kong(848) }->\text { Singapore(931) } \\
->\text { Colombo(1019) }->\text { Salalah(1111) }->\text { Southampton(1344) }\end{array}$ \\
\hline 11 & 1500 & $\begin{array}{l}\text { Brisbane(0) } \rightarrow \text { Sydney(51) } \rightarrow \text { Melbourne(109) } \rightarrow \text { Adelaide(164) }->\text { Fremantle(275) }-> \\
\text { Colombo(506) } \rightarrow \text { Salalah(639) } \rightarrow \text { Southampton(994) } \rightarrow \text { Salalah(1349) } \rightarrow> \\
\text { Colombo(1482) } \rightarrow \text { Brisbane(1848) }\end{array}$ \\
\hline 12 & 5000 & $\begin{array}{l}\text { Yantian(0) -> Southampton(513) -> Sokhna(700) -> Jeddah(756) -> Port Klang(994) -> } \\
\text { Singapore(1028) -> Manila(1119) }->\text { Yantian(1176) }\end{array}$ \\
\hline
\end{tabular}


Table 3 Computational results

\begin{tabular}{|c|c|c|c|c|c|c|c|c|c|c|}
\hline ID & $\begin{array}{c}\text { Total } \\
\text { demand }\end{array}$ & $\alpha$ & $\beta$ & $\begin{array}{l}\text { Total } \\
\text { cost }\end{array}$ & Slot cost & \#slots & $\begin{array}{c}\text { Transship } \\
\text { cost }\end{array}$ & $\begin{array}{l}\text { Transship } \\
\text { volume }\end{array}$ & $\begin{array}{c}\text { Cost of } \\
\text { transit time }\end{array}$ & $\begin{array}{l}\text { Reversed } \\
\text { ship routes }\end{array}$ \\
\hline & & & 0 & 11872 & 1125 & 460 & 4543 & 19252 & 6203 & \\
\hline \multirow[t]{3}{*}{1} & 22054 & 0.5 & 3 & 11445 & 1127 & 460 & 4578 & 19402 & 5738 & $10,11,12$ \\
\hline & & & Imp & $3.6 \%$ & $-0.2 \%$ & $0.0 \%$ & $-0.8 \%$ & $-0.8 \%$ & $7.5 \%$ & \\
\hline & & & 0 & 18764 & 1152 & 460 & 5287 & 19441 & 12323 & \\
\hline \multirow[t]{3}{*}{2} & 22054 & 1 & 3 & 17848 & 1155 & 460 & 5328 & 19589 & 11364 & $10,11,12$ \\
\hline & & & $\operatorname{Imp}$ & $4.9 \%$ & $-0.3 \%$ & $0.0 \%$ & $-0.8 \%$ & $-0.8 \%$ & $7.8 \%$ & \\
\hline & & & 0 & 32043 & 3673 & 1719 & 6487 & 18860 & 21882 & \\
\hline \multirow[t]{3}{*}{3} & 22054 & 2 & 3 & 30465 & 2159 & 962 & 6664 & 19373 & 21641 & $10,11,12$ \\
\hline & & & Imp & $4.9 \%$ & $41.2 \%$ & $44.0 \%$ & $-2.7 \%$ & $-2.7 \%$ & $1.1 \%$ & \\
\hline & & & 0 & 8829 & 0 & 0 & 3782 & 16029 & 5046 & \\
\hline \multirow[t]{3}{*}{4} & 17643 & 0.5 & 3 & 8518 & 0 & 0 & 3813 & 16157 & 4705 & $10,11,12$ \\
\hline & & & Imp & $3.5 \%$ & $0.0 \%$ & $0.0 \%$ & $-0.8 \%$ & $-0.8 \%$ & $6.8 \%$ & \\
\hline & & & 0 & 14425 & 0 & 0 & 4414 & 16228 & 10011 & \\
\hline \multirow[t]{3}{*}{5} & 17643 & 1 & 3 & 13784 & 0 & 0 & 4474 & 16449 & 9310 & $10,11,12$ \\
\hline & & & Imp & $4.4 \%$ & $0.0 \%$ & $0.0 \%$ & $-1.4 \%$ & $-1.4 \%$ & $7.0 \%$ & \\
\hline & & & 0 & 25345 & 1113 & 604 & 5709 & 16597 & 18522 & \\
\hline \multirow[t]{2}{*}{6} & 17643 & 2 & 3 & 24168 & 273 & 145 & 5896 & 17142 & 17998 & $7,10,11$ \\
\hline & & & Imp & $4.6 \%$ & $75.5 \%$ & $76.0 \%$ & $-3.3 \%$ & $-3.3 \%$ & $2.8 \%$ & \\
\hline
\end{tabular}

